\title{
Analisis Ketahanan Energi Perkotaan di Provinsi Lampung dengan Metoda 4a (Studi Kasus: Kota Bandar Lampung, Kota Metro, dan Kabupaten Lampung Selatan)
}

\author{
Yudha Rahman ${ }^{1}$, Citra Persada ${ }^{2}$, Asirin ${ }^{3}$ \\ ${ }_{1,3}$ Institut Teknologi Sumatera, Lampung Selatan \\ 2Universitas Lampung, Bandar Lampung \\ Correspondence e-mail: yudha.rahman@pwk.itera.ac.id
}

\begin{abstract}
Abstrak. Kemandirian energi dan ketahanan energi nasional merupakan tujuan dari kebijakan pengelolaan energi yang diatur dalam Undang-Undang No 30 tahun 2007 tentang Energi. Ketahanan energi (energy security) digambarkan dengan indikator 4A antara lain ketersediaan fisiknya (availability), kemudahan mendapatkannya (accessibility), keterjangkuan harganya (affordability), serta kualitasnya yang dapat diterima (acceptability). Dari kondisi permasalahan Energi Indonesia, maka diperlukan kajian yang bisa menggambarkan kondisi konsumsi dan ketahanan energi untuk Provinsi Lampung dan berbagi macam alternatif solusi penyelesaiannya. Dalam penelitian ini diambil 3 Kota di Provinsi Lampung yaitu Kota Bandar Lampung, Kota Metro, dan Kabupaten Lampung Selatan. Tujuan dari Penelitian ini adalah menganalisis Ketahanan Energi Perkotaan Di Provinsi Lampung dengan Metoda 4A (Availability, Accessibility, Affordability, dan Acceptability) dengan Studi Kasus Kota Bandar Lampung, Kota Metro, dan Kabupaten Lampung Selatan. Metode penelitian yang digunakan adalah penelitian kualitatif deskriptif dalam mendeskripsikan dan menggambarkan ketahanan energi tersebut. Dari hasil penelitian dari segi Avaibility menurun, Accesibility belum stabil, dari segi affordability kurangnya informasi standar harga, dan dari segi Acceptability masih terdapat keraguan di masyarakat akan mutu dari BBM dan listrik yang dikonsumsi.
\end{abstract}

Kata kunci : Area Perkotaan; Energi Baru dan Terbarukan; Ketahanan Energi

Abstract. Energy independence and national energy security are the objectives of the energy management policy regulated in Law No. 30 of 2007 on Energy. Energy security is illustrated by the 4A indicator, including its availability (availability), accessibility, affordability, and acceptability. From the condition of Energy Indonesia problem, it is necessary to study that can describe the condition of consumption and energy security for Lampung Province and share various alternative accomplishments. In this study were taken in 3 cities including Lampung Province namely Bandar Lampung City, Metro City, and South Lampung Regency. The purpose of this research is to analyze Urban Energy Security in Lampung Province with 4 A Method (Availability, Accessibility, Affordability, and Acceptability) with Case Study of Bandar Lampung City, Metro City, and South Lampung Regency. The research method used is descriptive qualitative research in describing and describe the energy security. From the Availability research decrease, the accessibility is not stable yet, in terms of affordability of lack of standard price information, and in terms of Acceptability there is still doubt in the community about the quality of fuel and electricity consumed

Keywords : Energy Security; Renewable Energy; Urban Area

\section{PENDAHULUAN}

Menurut Dewan Energi Nasional/DEN (2016) "Ketahanan energi" adalah suatu kondisi terjaminnya ketersediaan energi, akses masyarakat terhadap energi pada harga yang terjangkau dalam jangka panjang dengan tetap memperhatikan perlindungan terhadap lingkungan hidup. Ketahanan energi di perkotaan perlu memahami beberapa aspek, diantaranya suplai energi, peragaman sumber energi serta efisiensi dan konservasi energi ( Eicker et. Al, 2015 dalam Sagala et,.al 2016). Maka dalam hal ini Kota-kota harus meningkatkan ketahanan karena kompleksitas persoalan secara global dapat mempengaruhi kota baik dalam kebijakan, ekonomi, energi, air, dan kebencanaan. Penggunaan Konsumsi energi total tertinggi pada periode 2000-2014 terjadi pada sektor industri, diikuti rumah tangga dan tranportasi, serta yang paling rendah adalah komersial dan sektor lainnya. Tetapi rata-rata kenaikan pertumbuhan tahunan paling tinggi adalah sektor transportasi sebesar $6,46 \%$. Hal ini disebabkan oleh jumlah kendaraan di Indonesia yang meningkat tajam dari 19 juta kendaraan pada tahun 2000 menjadi 114 juta kendaraan pada tahun 2014 dengan rata-rata kenaikan per tahunnya sebesar 13,7\%. Menurut Nugroho (2014), Pertambahan penduduk (termasuk migrasi dari desa-desa ke kota), serta perubahan gaya hidup yang semakin energy-intensive, permintaan terhadap energi terus tumbuh di Indonesia. Dalam lima tahun mendatang (2015-2019), diperkirakan permintaan energi di Indonesia diperkirakan akan tumbuh dengan laju sebesar 5-6 persen untuk energi primer, dan 7-8 persen per tahun untuk energi total. Untuk Provinsi Lampung, sektor transportasi mengalami kenaikan jumlah hampir 10 kali lipat selama 10 tahun yaitu Jumlah Kendaraan Bermotor berjumlah 291.059 pada tahun 2000 menjadi 2.755.953 pada tahun 2014. Kenaikan jumlah kendaraan pada sektor transpotasi ini tentu memberi kontribusi terhadap konsumsi energi pada sektor Transportasi baik di Kota Bandar Lampung sampai konsumsi energi Nasional. Meningkatnya laju pertumbuhan konsumsi energi dari sektor transportasi di Lampung tidak terlepas dari faktor pertumbuhan penduduk dan kegiatan ekonominya. Hal ini dikarenakan Kota Bandar Lampung dan daerah kota disekitarnya merupakan daerah transmigran karena banyaknya migrasi masyarakat dari Pulau Jawa sejak tahun 1980an. Hal ini juga didorong oleh tingkat pertumbuhan penduduk yang tinggi dengan berbagai kegiatan ekonomi sehingga membantu menyumbang pada tingginya angka konsumsi energi di Indonesia.

Indonesia memiliki beberapa potensi sumber daya energi fosil diantaranya minyak bumi, gas bumi dan batubara. Dari data rasio cadangan produksi sumber energi fosil yang diterbitkan oleh BPPT tahun 2014, 
potensi pemanfaatan sumber batubara akan bertahan hanya selama 70 tahun, Gas Bumi bertahan selama 37 tahun, dan minyak bumi akan habis dalam waktu 12 tahun jika tidak ada ditemukannya cadangan energi baru (BPPT, 2016). Cadangan ini bahkan akan lebih cepat habis karena kecenderungan produksi energi fosil yang terus meningkat. Dengan tingkat ketergantungan Indonesia yang tinggi terhadap energi fosil yang mencapai $96 \%$, maka bisa diprediksi tidak akan lama lagi Indonesia bahkan Provinsi Lampung akan mengalami krisis energi. Menurut Nugroho (2014) Ketahanan energi (energy security) digambarkan dengan metoda yang memiliki indikator 4A: bagaimana ketersediaan fisiknya (availability), bagaimana kemudahan mendapatkannya (accessibility), bagaimana keterjangkuan harganya (affordability), serta bagaimana kualitasnya yang dapat diterima (acceptability). Dari beberapa kondisi tersebut diperlukan kajian yang bisa menggambarkan kondisi konsumsi dan ketahanan energi untuk Provinsi Lampung dan berbagi macam alternatif solusi penyelesaiannya. Dalam penelitian ini diambil 3 Kota di Provinsi Lampung yaitu Kota Bandar Lampung, Kota Metro, dan Kabupaten Lampung Selatan. Kota-kota ini dipilih untuk mewakali 3 karakteristik kota di Provinsi Lampung yaitu Bandar Lampung Sebagai Kota Besar, Kota Metro sebagai Kota Sedang, dan Kalianda (Kabupaten Lampung Selatan) sebagai Kota Kecil. Kota-kota ini dipilih untuk mempresentasikan perwakilan ketahanan energi dari 3 kelas karakteristik kota di Provinsi Lampung. Kota-kota kecil dan menegah sering terlupakan, padahal kota tersebut dapat mempresentasikan perkembangan aktivitas Perkotaan baik untuk Provinsi Lampung ataupun Indonesia. Jika dari sekarang tidak memiliki pengelolaan energi dengan baik, suatu saat kota tersebut bisa lumpuh padahal Lampung punya Potensi EBT (Energi Baru dan Terbarukan) yang cukup dari berbagai jenis EBT yang ada

Artikel dimulai dengan penjelasan latar belakang, yaitu alasan perlu dilakukannya penelitian, yang didukung referensi/literatur pendukung. Referensi tidak diperkenankan menggunakan sumber yang tidak baku seperti wikipedia ataupun blog, dst (Abdul, 2017). Editor (2018) mensyaratkan agar artikel orisinil dan bukan merupakan plagiat hasil karya orang lain. Tujuan dituliskan pada bagian akhir latar belakang. Jumlah referensi minimum yang digunakan delapan. Penulisan referensi dan kutipan mengacu pada APA style.

\section{METODE PENELITIAN Data dan Metode}

Penelitian ini membahas tentang Analisis Ketahanan Energi Perkotaan Di Provinsi Lampung dengan metoda menggunakan Indikator 4A (Availability, Accessibility, Affordability, dan Acceptability) dengan Studi Kasus: Kota Bandar Lampung, Kota Metro, Dan Kabupaten Lampung Selatan. Untuk mengetahui bagaimana bentuk ketahanan energi tersebut maka digunakan Metode Penelitian Kualitatif. Metode penelitian yang digunakan adalah penelitian kualitatif deskriptif. Metode penelitian kualitatif deskriptif adalah cara penelitian memahami kejadian berdasarakan prinsip dasar penelitian kualitatif yang diungkapkan melalui penjabaran-penjabaran diskriptif untuk mengambil kesimpulan penelitian. Dalam penelitian ini dilakukan survey Instansional sebagai langkah awal, Survey kepustakaan dan dokumen pendukung, observasi lapangan, dan wawancara sebagai verifikasi kepada beberapa pihak terkait energi

\section{Gambaran Umum Wilayah}

Wilayah Penelitian adalah 3 Kabupaten Kota di Bandar Lampung yang berdekatan secara administrasi dan saling berinteraksi. Wilayah studi yaitu Kota Bandar Lampung, Kota Metro, dan Kabupaten Lampung Selatan. Kota-kota ini dipilih untuk mewakali 3 karakteristik kota di Provinsi Lampung yaitu Bandar Lampung Sebagai Kota Besar, Kota Metro sebagai Kota Sedang, dan Kalianda (Kabupaten Lampung Selatan) sebagai Kota Kecil. Wilayah studi penelitian ini telah melaksanakan dan memanfaatkan beberapa sumber energi EBT

\section{Kajian Literatur}

Di Indonesia, definisi dari "Ketahanan Energi" belum didefinisikan dengan jelas/rinci di dalam produk hukum yang berlaku terkait energi. Menurut Dewan Energi Nasional/DEN (ketahananenergi.com, 2016) "Ketahanan energi" adalah suatu kondisi terjaminnya ketersediaan energi, akses masyarakat terhadap energi pada harga yang terjangkau dalam jangka panjang dengan tetap memperhatikan perlindungan terhadap lingkungan hidup. Nugroho (2015) mengusulkan definisi dari "Ketahanan Energi" sebagai "kondisi terjaminnya ketersediaan energi serta akses masyarakat terhadap energi pada harga yang terjangkau dan mutu yang diterima, melalui suatu bauran energi yang sehat dan berkelanjutan." Berikut Bagan yang menjelaskan Kondisi Energi Nasional saat ini serta Kondisi yang diharapkan :

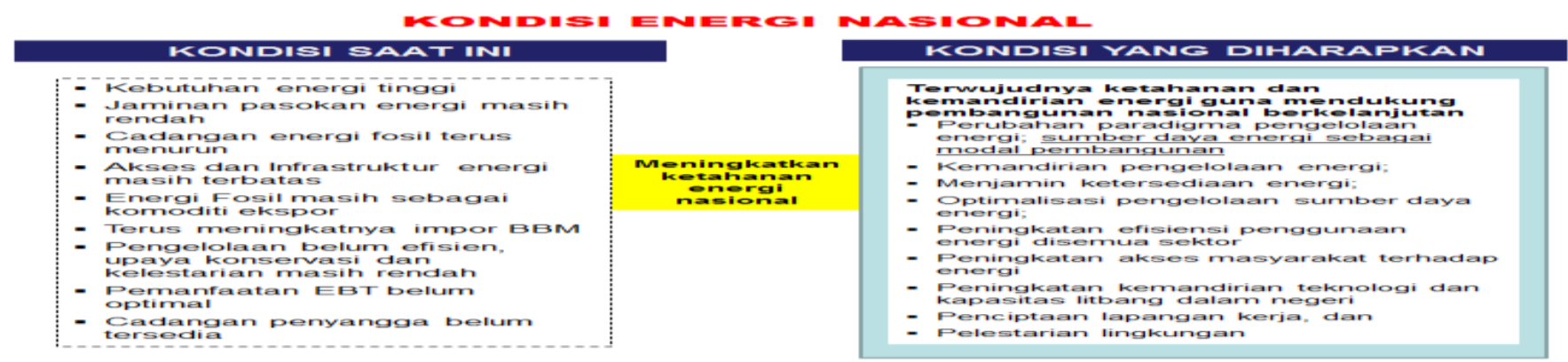

Sumber : Dewan Energi Nasional, 2017

Gambar 1. Kondisi Energi Nasional 
Menurut Nugroho (2014), secara umum ketahanan energi juga digambarkan melalui elemen bauran energi (energy mix) serta keberlanjutan (sustainability) dari sistem penyediaan permintaan energi yang ada. Nugroho (2014) juga menjabarkan Ketahanan Energi (energy security) dengan Indikator 4A yaitu sebagai berikut :

1. Ketersediaan fisiknya (availability)

2. Kemudahan mendapatkannya (accessibility)

3. Keterjangkuan harganya (affordability),

4. Kualitas yang dapat diterima (acceptability).

Dari 4A Indikator yang dimaksud, terdapat beberapa tantangan/permasalahan seiring dengan pertumbuhan konsumsi energi masyarakat perkotaan/ Indonesia menghadapi berbagai tantangan/permasalahan ketahanan energi. Permasalahan tersebut dapat dijabarkan per indikator sebagai berikut :

- Dari segi "availability" terdapat ancaman serius bahwa kemampuan untuk menyediakan energi secara nasional menurun, ditunjukkan dengan merosotnya kapasitas produksi (khususnya minyak bumi). Sementara itu, untuk memenuhi kebutuhan energi di dalam negeri, impor minyak bumi (baik crude oil maupun produk minyak) serta LPG (liquefi ed petroleum gas) terus meningkat

- Dari segi "Accesibility" terhadap produk energi persoalan yang terjadi ditunjukkan misalnya dengan rasio elektrifikasi yang masih rendah (dibandingkan negaranegara ASEAN, misalnya), serta banyaknya rumah tangga di desa-desa yang belum terlistriki. Di samping itu, "energy modern" seperti bahan bakar minyak (BBM) dan gas bumi juga belum menjangkau banyak penduduk yang tinggal di tempat terpencil di pegunungan/pulau-pulau kecil

- Dari segi "affordability" terjadi permasalahan dimana harga energi, baik BBM atau listrik selalu diperdebatkan. Apakah harga BBM yang ditetapkan Pemerintah itu wajar nilainya? Apakah masyarakat dapat menjangkau harga BBM dan listrik yang ditetapkan itu? Sebaliknya, dengan menetapkan harga BBM yang "murah" kepada masyarakat di dalam negeri apakah Pemerintah "dapat menjangkau" biaya penyediaannya, dalam pengetian tidak mengorbankan APBN untuk membiayai pos-pos pengeluaran lainnya.

- Dari segi "Acceptability" sering dikaitkan dengan mutu dari energi yang dipakai. Mutu BBM yang dikonsumsi ataupun mutu dari listrik yang dipergunakan masih merupakan permasalahan bagi masyarakat

- Dari sisi bauran energi, tantangan yang besar adalah masih masih tingginya ketergantungan pada bahan bakar fosil (khususnya minyak bumi), yang berarti pangsa pemanfaatan energi terbarukan yang masih rendah. Ketergantungan berlebihan pada bahan bakar fosil juga menimbulkan pertanyaan pada aspek keberlanjutan (sustainability) dari sistem pemanfaatan energi yang diterapkan di Indonesia.

Saat ini, sumber-sumber energi terbarukan banyak, porsi produksi energi masih bertumpu pada bahan bakar fosil. Sementara itu, porsi energi terbarukan ternyata berkurang. Oleh karena itu. Hal ini masih menjadi tantangan yang besar bagi perkotaan di Indonesia termasuk untuk Provinsi Lampung. Oleh karena itu kriteria karakteristik dan kapasitas sumber energi mengacu kepada jenis-jenis sumber energi yang terdapat di setiap kota (diversifying). Semakin banyak sumber energi, maka semakin baik sebuah kota memiliki akses energi yang baik. Di samping itu, kapasitas yang cukup untuk setiap kota akan membantu ketersediaan energi

\section{HASIL DAN PEMBAHASAN Potensi Energi Baru Terbarukan (EBT) di wilayah studi}

Dalam Rencana Strategis Dinas Energi dan Sumber Daya Mineral Provinsi Lampung tahun 20152019 terkait Isu ketersediaan energi menyatakan bahwa pertambahan penduduk yang terus meningkat dari tahun ketahun menyebabkan semakin bertambahnya kebutuhan energi, khususnya minyak dan gas. Kebutuhan energi yang terjadi tidak diimbangi dengan peningkatan penyediaan energi, hal ini disebabkan cadangan energi tertutama yang berasal dari bahan bakar fosil cadanganya semakin kecil, yang pada akhirnya akan dihadapkan pada masalah kerentanan energi yang berpotensi terhadap terjadinya krisis energi. Hal ini merupakan sebuah ancaman serius yang dapat mengganggu proses pembangunan di wilayah Provinsi Lampung. Pertumbuhan penduduk di wilyah transmigrasi Provinsi Lampung menyebabkan mulai berkurangnya pasokan ketersediaan energi. Kewenangan daerah termasuk Pemerintah Provinsi Lampung yang dijelaskan dalam Rencana Strategisnya terkait isu energi ini adalah bagaimana mengendalikan distribusi bahan bakar minyak agar tepat sasaran guna mendukung usaha masyarakat, khususnya sektor Usaha Kecil dan Menengah (UKM) dan pasokan ke fasilitas vital seperti pembangkit-pembangkit listrik. Dari isu akan ketersediaan energi tersebut juga terdapat peluang terkait Energi di Provinsi Lampung yaitu sebagai berikut : a. Potensi Energi Baru Terbarukan (EBT) masih sangat besar untuk dilakukan pengembangan, seperti biomasa, biogas, biofuel, dan gas rawa

b. Kebutuhan bahan bakar minyak setiap mengalami peningkatan sejalan dengan meningkatnya jumlah penduduk dan UMKM

Untuk menjelaskan kasus diatas, berikut Distribusi Potensi Energi Baru dan Terbarukan di tiga Kota Provinsi Lampung yang menjadi wilayah studi kasus dalam penelitian ini yaitu sebagai berikut :

\section{Potensi Biomassa}

Biomassa adalah bahan organik yang dihasilkan melalui pross fotosintetik, baik berupa produk maupun buangan. Sumber energi biomassa mempunyai beberapa kelebihan antara lain merupakan sumber energi yang dapat diperbaharui (renewable) sehingga dapat menyediakan sumber energi secara berkesinambungan (suistainable) Potensi Biomassa pada wilayah studi terdiri dari padi dan kelapa sawit. 
Yudha Rahman, et al, Analisis Ketahanan Energi Perkotaan di Provinsi Lampung dengan Metoda 4a (Studi Kasus: Kota Bandar Lampung, Kota Metro, dan Kabupaten Lampung Selatan)

Data mengenai potensi biomassa pada wilayah penelitian tersaji dalam tabel 1 berikut ini :

Tabel 1 Potensi Biomassa pada wilayah penelitian

\begin{tabular}{|c|c|c|c|c|}
\hline \multirow[t]{2}{*}{ No. } & \multirow[t]{2}{*}{ Kabupaten/Kota } & \multicolumn{3}{|c|}{ Panen (ton) } \\
\hline & & Padi & Tebu & Kelapa Sawit \\
\hline 1 & Bandar Lampung & 8,996 & - & 24 \\
\hline 2 & Metro & 18,297 & - & 5 \\
\hline 3 & Lampung Selatan & 469,457 & - & 6,671 \\
\hline
\end{tabular}

Sumber : Dinas ESDM Provinsi Lampung, 2017

Potensi Energi Biomassa ini bisa dikonversikan menjadi sumber energi listrik. Potensi biomassa di konversikan menjadi energi listrik dengan satuan KWh.
Konversi Biomassa menjadi energi listrik pada wilayah penelitian tersaji dalam tabel 2 berikut ini :

Tabel 2 Potensi Biomassa Konversi ke KWh pada wilayah Penelitian

\begin{tabular}{lllccc}
\hline No. & Kabupaten/Kota & \multicolumn{2}{c}{ Besaran Potensi Energi Yang Dapat Dibangkitkan (KWh) } & Jumlah (KWh) \\
& & Padi & \multicolumn{2}{c}{ Tebu } & Kelapa Sawit \\
\hline 1 & Bandar Lampung & 913,094 & 3,435 & 916,529 \\
2 & Metro & $1,857,146$ & - & 716 & $1,857,861$ \\
3 & Lampung Selatan & $47,649,886$ & - & 954,828 & $48,604,713$ \\
\hline
\end{tabular}

Sumber : Dinas ESDM Provinsi Lampung, 2017

Dari potensi biomassa di wilayah studi, Kabupaten Lampung Selatan memiliki pasokan Jumlah Potensi biomassa yang paling besar yaitu 48,604,713 KWh karena wilayah ini lebih memiliki karakteristik wilayahpertanian yang lebih besar dibandingkan wilayah lainnya.

\section{Potensi Biogas}

Biogas merupakan gas yang dihasilkan oleh bakteri metanogenik anaerobik (bakteri penghasil gas metan yang hanya dapat hidup dalam kondisi bebas oksigen) dari proses perombakan bahan - bahan organik seperti limbah kotoran sapi, babi, bahkan manusia. Secara alami biogas banyak terdapat di sawah atau rawa. Biogas terutama tersusun dari gas metan (55$75 \%$ ) dan karbondioksida (25-45 \%). Karena sifat gas metan yang mudah terbakar, maka biogas dapat dipakai sebagai sumber energi alternatif bagi masyarakat. Data mengenai potensi Biogas dari berbagai ternak pada wilayah penelitian tersaji dalam tabel 3 berikut ini :

Tabel 3 Potensi Biogas pada wilayah Penelitian

\begin{tabular}{|c|c|c|c|c|c|c|c|}
\hline \multirow[t]{2}{*}{ No. } & \multirow{2}{*}{ Kabupaten/Kota } & \multicolumn{6}{|c|}{ Potensi Biogas (ekor) } \\
\hline & & Sapi & Kerbau & Kambing & Domba & Unggas & Babi \\
\hline 1 & Bandar Lampung & 2,103 & 228 & 4,361 & 167 & 111,770 & 0 \\
\hline 2 & Metro & 5,949 & 413 & 9,972 & 2,487 & 1,284,223 & 244 \\
\hline 3 & Lampung Selatan & 110,214 & 2,321 & 357,048 & 7,249 & $21,571,194$ & 6,709 \\
\hline
\end{tabular}

Sumber : Dinas ESDM Provinsi Lampung, 2017

Potensi Biogas bisa dikonversi setara Liter minyak. Konversi Biogas menjadi minyak dengan satuan liter pada wilayah penelitian tersaji dalam tabel 4 dibawah ini :

Tabel 4 Potensi Biogas (setara liter minyak) pada wilayah Penelitian

\begin{tabular}{|c|c|c|c|c|c|c|c|c|}
\hline & \multirow[t]{2}{*}{ Kabupaten/Kota } & \multicolumn{6}{|c|}{$\begin{array}{c}\text { Besaran Potensi Energi Yang } \\
\text { Dapat Dibangkitkan (SLM = Setara Liter Minyak) }\end{array}$} & \multirow{2}{*}{$\begin{array}{l}\text { Potensi } \\
\text { Biogas } \\
\text { (SLM) }\end{array}$} \\
\hline & & Sapi & Kerbau & Kambing & Domba & Unggas & Babi & \\
\hline 1 & Bandar Lampung & 472,071 & 51,180 & 54,385 & 2,083 & 138,235 & 0 & 717,954 \\
\hline 2 & Metro & $1,335,402$ & 92,708 & 124,359 & 31,015 & $1,588,297$ & 7,303 & $3,179,084$ \\
\hline 3 & Lampung Selatan & $24,740,288$ & 521,006 & $4,452,686$ & 90,401 & $26,678,754$ & 200,800 & $56,683,935$ \\
\hline
\end{tabular}

Sumber : Dinas ESDM Provinsi Lampung, 2017

Potensi Biogas dalam konversi SLM (Setara Liter Minyak) terbesar terdapat di Kabupaten Lampung Selatan karena wilyah ini memiliki wilayah pertanian dan ternak yang lebih besar dibandingkan Kota Bandar Lampung dan Kota Metro.

\section{Potensi Bioetanol}

Bioetanol merupakan ethanol yang dihasilkan dengan mempergunakan bahan-bahan organik atau biomassa. Beberapa hasil pertanian dapat dimanfaatkan untuk menghasilkan Bioetanol seperti : tebu, singkong, umbi, Limbah Padat Selulosa, Limbah cair, Buah, jagung, dan sebaginya. Berikut potensi bioetanol yang ada diwilayah studi serta konversi kedalam Kiloliter sumber energi pada tabel 5 dan table 6 berikut : 
Yudha Rahman, et al, Analisis Ketahanan Energi Perkotaan di Provinsi Lampung dengan Metoda 4a (Studi Kasus: Kota Bandar Lampung, Kota Metro, dan Kabupaten Lampung Selatan)

Tabel 5 Potensi Biotanol pada wilayah Penelitian

\begin{tabular}{llcccc}
\hline No. & Kabupaten/Kota & \multicolumn{3}{c}{ Potensi Bioethanol (ton) } \\
& & Jagung & Ubi Kayu & Ubi Jalar & Tebu \\
\hline 1 & Bandar Lampung & 231 & 2,551 & 345 & - \\
2 & Metro & 4,460 & 5,563 & 432 & - \\
3 & Lampung Selatan & 632,137 & 150,920 & 3,843 & - \\
\hline
\end{tabular}

Sumber : Dinas ESDM Provinsi Lampung, 2017

Tabel 6 Potensi Bioetanol (Konversi ke kiloliter) pada wilayah Penelitian

\begin{tabular}{|c|c|c|c|c|c|c|}
\hline \multirow[t]{2}{*}{ No. } & \multirow[t]{2}{*}{ Kabupaten/Kota } & \multicolumn{4}{|c|}{$\begin{array}{c}\text { Bioethanol Yang Dapat Dihasilkan } \\
\text { Dalam } 1 \text { Tahun (KL) }\end{array}$} & \multirow[t]{2}{*}{$\begin{array}{c}\text { Potensi } \\
\text { Bioethanol (KL) }\end{array}$} \\
\hline & & Jagung & Ubi & Ubi Jalar & Tebu & \\
\hline 1 & Bandar Lampung & 96 & 425 & 58 & -- & 579 \\
\hline 2 & Metro & 1,858 & 927 & 72 & -- & 2,857 \\
\hline 3 & Lampung Selatan & 263,390 & 25,143 & 641 & -- & 289,174 \\
\hline
\end{tabular}

Sumber : Dinas ESDM Provinsi Lampung, 2017

Potensi bioethanol terbesar terdapat pada wilayah Lampung Selatan dibandingkan wilayah lainnya karena Lampung Selatan memiliki wilayah studi yang lebih luas dengan banyaknya potensi pertanian dan perkebunan dibandingkan Kota Bandar Lampung dan Kota Metro.

\section{Potensi Tenaga Surya}

Berdasarkan hasil penelitian oleh P3TKEBTKE, Provinsi Lampung memiliki kelas intensitas antara 4,713 - 4,974 Kwh/m2/hari (Dinas ESDM Provinsi Lampung, 2017). Salah satu Strategi yang digunakan untuk ketersediaan energy di Provinsi Lampung adalah dengan mengalihkan penggunaan energi dari minyak bumi (fosil) ke energi terbarukan (bukan fosil). Hal ini merupakan salah satu Rencana Pembangunan sekttor energi yang direncanakan untuk Provinsi Lampung. Akan tetapi terdapat beberapa kendala dalam hal implementasi rencana. Kendala yang ada antara lain sebagai berikut :

- Mahalnya penerapan teknologi pemanfaatan energi baru terbarukan karena sebagian besar berasal dari luar negeri

- Institusi yang mengaplikasikan teknologi energi baru terbarukan sangat terbatas

- Peran akademisi belum terimplementasikan secara konkrit dalam penemuan teknologi energi baru terbarukan secara local

- Untuk saat ini biaya produksi energi baru terbarukan lebih mahal daripada bahan bakar fosil mengingat adanya subsidi layanan umum bagi Pertamina maupun PLN

- Harga BBM lebih murah dibandingkan dengan harga energi terbarukan yang harga dasar produksinya lebih mahal

Terkait biogas harus dipetakan sesuai jumlah ternak, biofuel dan biomassa dengan banyanyaknya tumbuhan singkong dan sawit. Kalau dilihat secara karakteristik tiga wilayah Kota Bandar Lampung, Metro, dan Lampung Selatan. Lampung Selatan memiliki potensi terbesar karena memiliki wilayah yang lebih luas sehingga kecenderungan potensinya lebih tinggi.

\section{Gambaran Ketahanan Energi dengan indikator 4A}

Untuk Analisis Ketahanan energi (energy security) digambarkan dengan indikator 4A : ketersediaan fisiknya (availability), kemudahan mendapatkannya (accessibility), keterjangkuan harganya (affordability), serta kualitasnya yang dapat diterima (acceptability). Berikut hasil analisis dari wawancara dengan Dinas ESDM Provinsi Lampung terkait ketahanan energi di wilayah studi :

- Untuk segi "availability" kemampuan untuk menyediakan energi di wilayah studi kajian menurun, ditunjukkan dengan merosotnya kapasitas dan impor minyak bumi (baik crude oil maupun produk minyak) serta LPG (liquefied petroleum gas) terus meningkat. Ketersediaan terkait Potensi EBT untuk tiga wilayah penelitian cukup ada pasokan yang bisa terus dikembangkan. Untuk potensi biogas pasokkan ternak sapi banyak juga diwilayah lain di Provinsi Lampung seperti di Lampung Timur dan Lampung Tengah.

- Untuk segi "Accesibility" persoalan akses energi listrik di wilayah studi kajian memiliki rasio elektrifikasi yang cukup stabil karena tingginya Rasio Elektifikasi untuk 3 wilayah ini yaitu : Bandar Lampung 93,58\%. Kota Metro 102,85\%, dan Kabupaten Lampung Selatan $79,27 \%$. Maka dalam hal ini wilayah studi kajian sudah teraliri listrik dan untuk energi modern seperti BB M (Bahan Bakar Minyak) sudah dapat dijangkau walau untuk daerah yang di pelosok sekalipun. Untuk kemudahan mendapatkan dari potensi EBT seperti biogari kotoran sapi sebenarnya mudah didapatkan karena potensi ternak masih banyak sebelum diolah. Namun setelah diolah, harus dimanfaatkan artinya harus punya dulu unit pemanfaatannya.

- Dari segi "Affordability" untuk keterjangkauan harga energi, baik BBM atau listrik masih menjadi permasalahan bagi masyarakat akibat kurang tahunya informasi standar harga untuk konsumsi energi tersebut. Standar harga BBM baik yang subsidi maupun non-subsidi masih menjadi kebingungan masyarakat akan standar harga BBM di Indonesia dibanding negara lain, maka dalam hal ini perlu adanya sosilisasi informasi standar harga dari pemerintah. Untuk keterjangkauan harga mengakses mengembangkan potensi EBT yang bisa dikembangkan saat ini masih terbatas karena agak mahalnya alat dan teknologi yang dibutuhkan.

- Dari segi "Acceptability" sering dikaitkan dengan mutu dari energi yang dipakai. Dalam hal ini masih terdapat keraguan di masyarakat akan mutu atau kualitas dari BBM dan listrik yang dikonsumsi. Terkait kualitas dari potensi EBT, masyarakat belum sepenuhnya bisa 
percaya kalau EBT ini bisa berkelanjutan karena kurangnya pengembangan produk potensi EBT.

\section{SIMPULAN}

Dari gambaran Potensi Energi Baru Terbarukan di wilayah studi terlihat bahwa Lampung Selatan memiliki potensi EBT yang lebih besar dibandingkan Kota Bandar Lampung dan Kota Metro. Hal ini terjadi karena Lampung selatan lebih dominan memiliki karakter wilayah pertanian, ternak, dan hasil laut. Potensi EBT ini pun baru sekedar potensi jika tidak ada teknologi yang ikut mengembangkan. Maka Rekomendasi terkait Potensi EBT ini adalah perlunya Pemanfaatan energi alternative sesegera mungkin, kerjasama berbagai pihak dalam mengembangkan potensi EBT yang belum dimanfaatkan, serta diperlukan perencanaan energi yang lebih komprehensif dan terintegerasi di Provinsi Lampung. Dari gambaran ketahanan energi untuk Provinsi Lampung terdapat beberapa rekomendasi seperti meningkatkan produksi potensi minyak dan gas bumi, mengurangi ketergantungan impor, memperbaiki akses keterjangkauan energi, memberda, mempercepat pengembangan potesi Energi Terbarukan dan memberdayakan masyarakat untuk menghemat energi. Jika dari sekarang tidak memiliki ketahanan energi dengan baik, suatu saat kota bisa lumpuh padahal Lampung punya Potensi EBT (Energi Baru dan Terbarukan) yang cukup dari berbagai jenis EBT

\section{DAFTAR PUSTAKA}

A Solichin, Eka. (2016). PLN Sebut Kondisi Kelistrikan Lampung Selama 2016 Masih Siaga dalam http://lampung.tribunnews.com/2016/03/16/plnsebut-kondisi-kelistrikan-lampung-selama-2016masih-siaga. Diakses Sabtu, 25 Maret 2017 $\leftarrow$ Website

Anonim. (2016) . Definisi Ketahanan Energi http://www.ketahananenergi.com/2016/05/definisiketahanan-energi/. Diakases Sabtu, 25 Maret $2017 \leftarrow$ Website

BPPT. (2016). Outlook Energi Indonesia 2016: Pengembangan Energi Untuk Mendukung Industri Hijau. Jakarta, Pusat Teknologi Pengembangan Sumber Daya Energi dan Industri Kimia, Badan Pengkajian dan Penerapan Energi. $\leftarrow$ Buku

BPS online Provinsi Lampung . 2017. http://lampung.bps.go.id/linkTabelStatis/view/id/39

6. Diakses Minggu, 26 Maret 2017. $\leftarrow$ Website

Dewan Energi Nasional. (2017). Ketahanan Dan Kemandirian Energi. Disampaikan Pada Seminar Nasional Fakultas Teknik, Universitas Lampung Lampung, 20 Maret $2017 \leftarrow$ Konferensi

Lehmann, S. (2015). A New Urban Agenda: Introduction to the Special Issue on "Sustainable Urban Development". Sustainability, 7(8), 10000-10006 $\leftarrow$ Jurnal

Moleong, Lexy .J. (2007). Metodologi Penelitian Kualitatif. Bandung : PT Remaja Rosdakarya. $\leftarrow$ Buku

Nugroho, Hanan. (2014). Ketahanan Energi Indonesia : Gambaran Permasalahan dan Strategi Memperbaikinya. Majalah Perencanaan
Pembangunan Edisi 02 Tahun XX September 2014. $\leftarrow$ Majalah

Sagala, S., Lubis, W., Amerid, Y., Prambudia, Y., (2015). Ketahanan Energi Perkotaan dan Pembangunan Rendah Karbon di Metropolitan Indonesia. 145179. $\leftarrow$ Jurnal

Undang-Undang No.30 Tahun 2007 tentang energi $\leftarrow$ Undang-Undang 